\title{
Attitude towards adherence to long term therapy
}

\section{Paramita Sarkar ${ }^{1}$; Abantika Bagchi ${ }^{2}$; Dipanwita Sarkar ${ }^{3}$; Rajesh K Dalal ${ }^{4}$; Swarnanka Chakrabarty ${ }^{5}$; Rivu Basu ${ }^{6}$}

${ }^{1}$ Post Graduate, Department of Community Medicine, Radha Gobinda Kar Medical College and Hospital, Kolkata 700004, West Bengal, India; ${ }^{2}$ Post Graduate, Department of Community Medicine, Radha Gobinda Kar Medical College and Hospital, Kolkata 700004, West Bengal, India; ${ }^{3}$ Post Graduate, Department of Community Medicine, Radha Gobinda Kar Medical College and Hospital, Kolkata 700004, West Bengal, India; ${ }^{4}$ Post Graduate, Department of Community Medicine, Radha Gobinda Kar Medical College and Hospital, Kolkata 700004, West Bengal, India; ${ }^{5}$ Post Graduate, Department of Community Medicine, Radha Gobinda Kar Medical College and Hospital, Kolkata 700004, West Bengal, India; ${ }^{6}$ Assistant Professor, Department of Community Medicine, Radha Gobinda Kar Medical College and Hospital, Kolkata 700004, West Bengal, India

\begin{tabular}{|c|c|c|c|c|c|c|c|c|}
\hline Abstract & Introduction & Methodology & Results & Conclusion & References & Citation & \multicolumn{2}{|c|}{ Tables / Figures } \\
\hline \multicolumn{9}{|c|}{ Corresponding Author } \\
\hline \multicolumn{8}{|c|}{$\begin{array}{l}\text { Dr Rivu Basu, Assistant Professor, Department of Community Medicine, Radha Gobinda Kar Medical College, } \\
\text { Kolkata 700004, West Bengal, India } \\
\text { E Mail ID: rivubasu83@gmail.com }\end{array}$} & 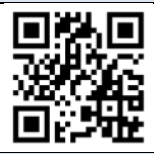 \\
\hline
\end{tabular}

\section{Citation}

Sarkar P, Bagchi A, Sarkar D, Dalal RK, Chakrabarty S, Basu R. Attitude towards adherence to long term therapy. Indian J Comm Health. 2020;32(1):39 - 42.

Source of Funding: Nil Conflict of Interest: None declared

\section{Article Cycle}

Received: 25/11/2019; Revision: 09/01/2020; Accepted: 22/02/2020; Published: 31/03/2020

This work is licensed under a Creative Commons Attribution 4.0 International License.

\section{Abstract}

Background: Chronic disease is a common public health problem worldwide. Adherence to long-term treatment is a key determinant of therapeutic success in patients with chronic diseases. Aim \& Objective: The purpose of the study was to know the people's attitude towards intake of drug, medication adherence and their relationship with socio demographic profile. Settings and Design: Data were collected from 729 individuals chronic disease sufferers chosen randomly from all 81 villages of Amdanga Block West Bengal through a household-based survey in a cross- sectional design. Methods and Material: A pre designed, pre tested, semi structured schedule containing socio-demographic profile and attitude among the respondents regarding adherence to long-term treatment. Statistical analysis used: To compare Attitude scores among different groups, median (IQR) attitude score was calculated and compared with Mann-Whitney $U$ test and Kruskal-Wallis test to know the level of significance of variables. $p$-value $<0.05$ considered statistically significant. Results: Attitude towards long-term adherence to treatment to chronic diseases were significantly associated to caste $(p=0.043)$, education $(p=0.001)$ and occupation ( $p=0.001$ ) of the study subject. Conclusions: Attitude towards long-term adherence to treatment to chronic diseases were significantly associated to caste, education and occupation.

\section{Keywords}

Adherence; Attitude; Chronic Disease; Household Survey; Long-Term Therapy

\section{Introduction}

Chronic diseases have one or more of the following characteristics: they are permanent, leave residual disability, are caused by irreversible pathological alteration, or may be expected to require a long period of supervision, observation or care.(1) Adherence to longterm therapy is defined as "the extent to which a person's behaviour - taking medication following a diet, and/or executing lifestyle changes, corresponds with agreed recommendations from a health care provider." $(2,3)$ In developed countries, adherence to long-term therapies in the general population is around $50 \%$ and is much lower in developing countries. It has also been observed that increasing the adherence interventions may have a far greater impact on the health of the population than any improvement in specific medical treatments.(4) Poor adherence to long-term therapies severely compromises the effectiveness of treatment making this a critical issue in population health both from the perspective of quality of life and of health economics.(2)

Attitude of patients toward medication, an important factor, depends on multiple factors like overall perception of medications as good or bad, effect and side effects of the medication, and willingness to opt for medication.(5) A positive attitude towards medication has a positive correlation with adherence. Attitude towards medication 
may directly or indirectly mediate the impact of illness. A negative attitude, delay or refusal of treatment may lead to adverse effect on illness. $(6,7)$

In the absence of a single definitive intervention to address non adherence the 'NICE Medicines Adherence Guidelines' amalgamate insights from trials of interventions and explanatory studies of nonadherence.(8) It is best understood in terms of the perceptual factors (e.g. beliefs and preferences) influencing motivation to start and continue with treatment.(9)

Adherence is also a multifactorial phenomenon and varies from population to population. $(10,11)$. Factors such as age, gender, socio-economic status, level of disease severity, complexity of prescribed medications, societal acceptance, poor patient related relationship, cost, forgetfulness, and presence of psychological problems have all been shown to affect the adherence in various populations. Furthermore, the perception of a patient toward medications itself can play a relatively major impact. $(12,13,14,15,16)$

\section{Aims \& Objectives}

To know the people's attitude towards intake of drug, medication adherence and their relationship with socio demographic profile.

\section{Material \& Methods}

It was a community based, observational descriptive study with cross-sectional design conducted at Amdanga community development block, North 24 Parganas, West Bengal which is the rural field practice area of R.G Kar Medical College and Hospital. Study was conducted for 1year - December 2017 to November 2018. Sample size calculation was done prior to the study by using the standard formula $\mathrm{N}=(\mathrm{Z} \alpha) 2 \mathrm{PQ} / \mathrm{I} 2$ where $\mathrm{Z} \alpha=1.96$ (taking the confidence interval of $95 \%), P=$ prevalence of adherence to medication due to chronic illness presumed to be $50 \%$ (maximum), $Q=(100-P)$ and $\mathrm{I}=$ allowable error was taken as $4 \%$.Taking the non-response rate of $20 \%$, the desired sample size was 720. Amdanga Block has 81 villages and from every village, 9 persons were selected for study. The final desired sample size becomes $=(81 \mathrm{X} 9)$ $=729$ persons. From every village of Amdanga, randomly 9 persons were selected for study. Individuals were selected by going to the centre of a village and finding out the direction to start survey by lottery method. In the selected direction consecutive houses were approached by left hand rule and one person from one household was selected until the required number of individuals from that village were interviewed. A pre-designed, pretested semi-structured scheduled questionnaire were use used to record the response of the study subjects. The questionnaire was designed to capture their sociodemographic profile and attitude among the respondents regarding adherence to long-term therapy. The persons having some Chronic disease for more than last 6 months from the starting of the data collection period, who gave their verbal consent after proper explanation of the purpose of this study were included in the study for interview. Ethical Clearance-Ethical clearance was obtained from the institutional ethics committee prior to the study. Data Analysis-The analysis was done on the basis of scalar-scoring method. Overall, there were 21 questions in the questionnaire for attitude part. The participant provides their agreement with each statement on a 5-point Likert scales as; 1= Strongly Disagree, 2= Disagree, 3= neither agree nor disagree, 4=Agree and $5=$ Strongly Agree. Also, reverse coding was used for negative statements. Thus, total attitude score was ranging from 21 to 105 . To compare Attitude scores among different groups, median (IQR) attitude score was calculated and compared with Mann-Whitney $U$ rest and Kruskal-Wallis test to know the level of significance of variables. $p$-value $<0.05$ considered statistically significant. Data obtained, were properly coded, compiled and were put in excel spreadsheet. IBM SPSS (version 16.0) software were used for data analysis.

\section{Results}

Table 1 shows the distribution of the study population according to their attitude towards adherence to long term therapy. Most (97.9\%) of respondent perceived that they were ill and needed to do something about their illness. Though most of them (69.1) think that they should follow advice completely to be cured, $11.1 \%$ does not agree with the fact. Similarly, regarding timely investigation and continuation of long-term medication, most of the respondent ( $66.7 \%$ and $82 \%$ respectively) think it should be done. Table 2 shows that there are significant difference in median attitude score among respondents according to socio-demographical variable such as caste, education and occupation. Schedule caste has more favorable attitude than general and others. Among education, attitude score gradually increase with higher educational level. Respondents who are class 12 pass and above have more favorable attitude towards adherence to long-term therapy. Similar picture is seen among occupational groups where semi-professional have most favorable attitude towards adherence to longterm therapy.

\section{Discussion}

In this study, among the socio demographic variables age $(p=0.144)$, sex $(p=0.162)$, religion $(p=0.860)$ were found to have no significant association with the attitude toward long term adherence to medications. Generally, in Indian context the needs of women are usually neglected by self or by other family members. As the cost for long term adherence to treatment for chronic disease is higher, they usually show less commitment for adherence to long term treatment. Caste was found to have significant association ( $p$ value $=0.043$ ) with attitude towards long term medication adherence. The difference of association 
among religion and caste which was found in this study, may be possibly due to the caste system structure in Indian society. A study by Ram Dushad et al. in Mysuru, India has found significant association with education and occupation.(17) Another study by Lemay j et al. in Kuwait has found significant association between level of education and medication adherence attitude.(18) Study by Eticha $T$. et al. says age, education and occupational status is significant association with attitude of long term adherence.(19) younger the age, the more committed was the person for long term adherence to medication. In our study, Education ( $p$ value $=0.001$ ) and occupation ( $p$ value $=0.001$ ) were found to have highly significant association with attitude towards adherence. Socio economic status (SES) had no significant association with attitude towards adherence $(p=0.511)$. The more is the level of education; the more is the commitment for intake of medications for long term to eradicate or keep the chronic disease in control. The higher the occupational status of a person, the more is his/her knowledge and commitment and affordability of taking long term medicines. SES is dependent upon education and occupational status of an individual. People with poor SES has low level of education and income. But the results in our study did not find any significant association between SES and attitude score unlike education and occupation.

\section{Conclusion}

Attitude towards long term adherence to treatment to chronic diseases are significantly associated to caste, education and occupation of study subject and not significantly associated with age, sex \& religion.

\section{Recommendation}

Education level of people should be improved by promoting education, preventing school dropout and starting adult education program with targeted interventions to economically deprived groups.

\section{Limitation of the study}

Due to the cross-sectional design change in attitude depending upon the years of disease, various other factors that may be associated could not be studied. Moreover, the attitude may change in due course due to health education, government interventions.

\section{Relevance of the study}

This study explored the adherence of long-term medication with respect to the attitude of the patient and also explored the attitudinal gradients in different socioeconomic strata. It has implications that people with poorer socio-economic strata, education do have poorer attitudes towards adherence of medications.

\section{Authors Contribution}

All authors have contributed equally.

\section{Acknowledgement}

We would like to thank our Professor and Head and all study participants for their co-operation

\section{References}

1. Dictionary of health services management, 2nd ed. Owing Mills, MD, National Health Publishing, 1982

2. Haynes RB. Determinants of compliance: The disease and the mechanics of treatment. Baltimore MD, Johns Hopkins University Press, 1979.

3. Rand CS. Measuring adherence with therapy for chronic diseases: implications for the treatment of heterozygous familial hypercholesterolemia. American Journal of Cardiology, 1993, 72:68D-74D.

4. Sabate E.WHO Adherence Meeting Report. Geneva, World Health Organization, 2001.

5. Hogan TP, Awad AG, Eastwood R. A self-report scale predictive of drug compliance in schizophrenics: reliability and discriminative validity. Psychol Med. 1983;13(1):177-83.

6. Yang J, Ko YH, Paik JW, Lee MS, Han C, Joe SH, et al. Symptom severity and attitudes toward medication: impacts on adherence in outpatients with schizophrenia. Schizophr Res. 2012;134(2-3):22631.

7. Chandra IS, Kumar KL, Reddy MP, Reddy CMPK. Attitudes toward Medication and Reasons for Non-Compliance in Patients with Schizophrenia. Indian J Psychol Med. 2014;36(3):294-8.

8. National Institute for Health and Clinical Excellence (2009) Medicines adherence: involving patients in decisions about prescribed medicines and supporting adherence CG76. London: National Institute for Health and Clinical Excellence.

9. Horne R, Weinman J, Barber N, Elliott RA, Morgan M (2006) Concordance, Adherence and Compliance in Medicine Taking: A conceptual map and research priorities. London: National Institute for Health Research (NIHR) Service Delivery and Organization (SDO) Programme. Available: http://www.sdo.Ishtm.ac.uk/sdo762004.html. Accessed October 17th 2019

10. DiMatteo MR. Variations in patients' adherence to medical recommendations: A quantitative review of 50 years of research. Med Care 2004;42:200-9.

11. Krousel-Wood M, Hyre A, Muntner P, Morisky D. Methods to improve medication adherence in patients with hypertension: Current status and future directions. Curr Opin Cardiol 2005;20:296-300.

12. Osterberg L, Blaschke T. Adherence to medication. N Engl J Med 2005;353:487-97.

13. . Payne KA, Esmonde-White S. Observational studies of antihypertensive medication use and compliance: Is drug choice a factor in treatment adherence? Curr Hypertens Rep 2000;2:515-24.

14. Lennon C, Hughes CM, McElnay JC, Johnston GD. Identification of psychosocial factors which influence patient adherence with antihypertensive medication. Int J Pharm Pract 2001;9:8.

15. Almas A, Hameed A, Ahmed B, Islam M. Compliance to antihypertensive therapy. J Coll Physicians Surg Pak 2006;16:23-6.

16. Vermeire $E$, Hearnshaw $H$, Van Royen $P$, Denekens J. Patient adherence to treatment: Three decades of research. A comprehensive review. J Clin Pharm Ther 2001;26:331-42.

17. Dushad R, Mintu M, Samaksha PB, Basavana GH, Dushad R, Mintu $M$, et al. A study of drug attitude and medication adherence and its relationship with the impact of illness among the mentally ill. Archives of Clinical Psychiatry (São Paulo) [Internet]. 2019 Aug [cited 2019 Nov 5];46(4):85-8. Available from http://www.scielo.br/scielo.php?script=sci abstract\&pid=S010160832019000400085\&lng=en\&nrm=iso\&tlng=en

18. $\mathrm{M} \sqcup$ Waheedi, Al-Sharqawi S. Medication adherence in chronic illness: do beliefs about medications | play a role? [Internet]. [cited 2019 Nov 5]. Available from: https://www.dovepress.com/ medication-adherence-in-chronic-illness-do-beliefs-aboutmedications 


\section{Tables}

\begin{tabular}{|c|c|c|c|c|c|}
\hline Statement & $\begin{array}{l}\text { Strongly } \\
\text { agree }\end{array}$ & Agree & Neutral & Disagree & $\begin{array}{l}\text { Strongly } \\
\text { disagree }\end{array}$ \\
\hline Felt ill & $119(16.3)$ & $595(81.6)$ & $3(0.4)$ & $9(1.2)$ & $3(0.4)$ \\
\hline Felt so much ill that need to do something & $132(18.1)$ & $549(75.3)$ & $5(0.7)$ & $43(5.9)$ & $0(0)$ \\
\hline Will be cured completely if follow advice & $27(3.7)$ & $477(65.4)$ & 144(19.8) & $76(10.4)$ & $5(0.7)$ \\
\hline Should do timely Investigation to control disease & $13(1.8)$ & $473(64.9)$ & $211(28.9)$ & $30(4.1)$ & $2(0.3)$ \\
\hline Should Continue long-term medication to control the disease & $21(2.9)$ & $577(79.1)$ & $52(7.1)$ & $79(10.8)$ & $0(0)$ \\
\hline Life style modification also required to control the disease & 14(1.9) & $544(74.6)$ & $150(20.6)$ & $20(2.7)$ & $1(0.1)$ \\
\hline The disease will not be cured if regular check-up is not done & $10(1.4)$ & $533(73.1)$ & 113(15.5) & $73(10)$ & $0(0)$ \\
\hline This disease cannot be controlled by any means & $10(1.4)$ & 123(16.9) & 225(30.9) & $353(48.4)$ & $18(2.5)$ \\
\hline Will not be able to perform job if regular check-up is not done & $15(2.1)$ & $599(82.2)$ & $46(6.3)$ & $67(9.2)$ & $2(0.3)$ \\
\hline For curing this disease, need to visit more qualified doctor & $32(4.4)$ & $339(46.5)$ & 144(19.8) & $195(26.7)$ & $19(2.6)$ \\
\hline Expected some Improvement immediately after taking medication & $11(1.5)$ & $597(81.9)$ & $74(10.2)$ & $47(6.4)$ & $0(0)$ \\
\hline $\begin{array}{l}\text { Will not be able to perform day to day activity and become dependent } \\
\text { on family member if regular check-up is not done }\end{array}$ & $9(1.2)$ & $546(74.9)$ & $93(12.8)$ & 78(10.7) & $3(0.4)$ \\
\hline Timing and process of taking regular medication is too complex & $9(1.2)$ & $73(10)$ & $63(8.6)$ & $544(74.6)$ & $40(5.5)$ \\
\hline Complication will develop if regular medication is not taken & $22(3.0)$ & $422(57.9)$ & $234(32.1)$ & $49(6.7)$ & $2(0.3)$ \\
\hline Irregular treatment may lead to loss of income & $15(2.1)$ & $605(83.0)$ & $45(6.2)$ & $62(8.5)$ & $2(0.3)$ \\
\hline Once mediation started it cannot be stopped & $24(3.3)$ & $465(63.8)$ & $191(26.2)$ & $46(6.3)$ & $3(0.4)$ \\
\hline Irregular treatment may lead to increased dose of further medication & $24(3.3)$ & $454(62.3)$ & 133(18.2) & $117(16.0)$ & $1(0.1)$ \\
\hline No improvement in disease even after medication & $13(1.8)$ & $169(23.2)$ & $18(2.5)$ & $457(62.7)$ & 72(9.9) \\
\hline Alternate medicine (AYUSH) is better than allopathy & $35(4.8)$ & $53(7.3)$ & 14(1.9) & $340(46.6)$ & $287(39.4)$ \\
\hline Disease Improved after medication as expected & $20(2.7)$ & $481(66.0)$ & $30(4.1)$ & 189(25.9) & $9(1.2)$ \\
\hline Should enjoy life carefree now, rest can be taken care of later & $0(0)$ & $9(1.2)$ & $11(1.5)$ & $339(46.5)$ & $370(50.8)$ \\
\hline
\end{tabular}

\section{TABLE 2 ATTITUDE SCORE REGARDING ADHERENCE TO LONG TERM THERAPY (N= 729)}

\begin{tabular}{|c|c|c|c|c|c|}
\hline \multicolumn{2}{|l|}{ Socio demographic variable } & Number & Percentage & Median (IQR) & $p$ value \\
\hline \multirow[t]{3}{*}{ Among age group \# } & Up to $40 y r$ & 141 & 19.3 & $76(73-80)$ & \multirow[t]{3}{*}{0.144} \\
\hline & $41-60 y r$ & 367 & 50.3 & $77(74-80)$ & \\
\hline & More than 60yr & 221 & 30.3 & $76(73-80)$ & \\
\hline \multirow[t]{2}{*}{ Among Sex ${ }^{\circledR}$} & Male & 308 & 42.2 & $77(74-80)$ & \multirow[t]{2}{*}{0.162} \\
\hline & Female & 421 & 57.8 & $76(73-80)$ & \\
\hline \multirow[t]{2}{*}{ Among religion ${ }^{\complement}$} & Hindu & 392 & 53.8 & $76(73-80)$ & \multirow[t]{2}{*}{0.860} \\
\hline & Muslim & 337 & 46.2 & $77(73-80)$ & \\
\hline \multirow[t]{3}{*}{ Among caste \# } & General & 626 & 85.9 & $76(73-80)$ & \multirow[t]{3}{*}{$0.043^{*}$} \\
\hline & SC & 54 & 7.4 & $77(73-82)$ & \\
\hline & Other & 49 & 6.7 & 75(71-79) & \\
\hline \multirow[t]{4}{*}{ Among Education \# } & Illiterate & 276 & 37.9 & $76(73-80)$ & \multirow[t]{4}{*}{$0.001^{*}$} \\
\hline & Class 4 pass & 372 & 51.0 & $76(73-80)$ & \\
\hline & Class 10 pass & 36 & 4.9 & $77(74-82)$ & \\
\hline & Class 12 pass \& Above & 45 & 6.2 & $80(76-84)$ & \\
\hline \multirow[t]{5}{*}{ Among Occupation\# } & Unemployed & 138 & 18.9 & $77(72-80)$ & \multirow[t]{5}{*}{$0.001^{*}$} \\
\hline & Unskilled Worker & 300 & 41.2 & $77(74-81)$ & \\
\hline & Skilled Worker & 74 & 10.2 & $75(71-79)$ & \\
\hline & Clerical, Shop Owner, Farmer & 198 & 27.2 & $76(73-79)$ & \\
\hline & Semi Professional & 19 & 2.6 & $81(76-86)$ & \\
\hline \multirow[t]{5}{*}{ Among socio-economic status\# } & Class I (Upper) & 20 & 2.7 & $77(76-80)$ & \multirow[t]{5}{*}{0.511} \\
\hline & Class II (upper middle) & 63 & 8.6 & $76(75-80)$ & \\
\hline & Class III (middle) & 141 & 19.3 & $76(73-80)$ & \\
\hline & Class IV (lower-middle) & 254 & 34.8 & $76.5(73-80)$ & \\
\hline & Class V (lower) & 251 & 34.4 & $76(73-80)$ & \\
\hline
\end{tabular}

